\title{
Síndrome de Sweet associada à policitemia vera
}

\author{
Sweet's syndrome associated withpolycythemiavera
}

\author{
Ângela Puccini Moreira ${ }^{1}$ \\ Neide Kalil Gaspar ${ }^{3}$ \\ Enoi Aparecida Guedes Vilar
}

\author{
Flávia Feijó de Souza² \\ Ada Lobato Quattrino ${ }^{4}$
}

\begin{abstract}
Resumo: A síndrome de Sweet pode estar associada a malignidades hematológicas, principalmente, à leucemia mieloide aguda, porém existem poucos relatos demonstrando a associação com a policitemia vera. Relata-se o caso de doente do sexo masculino, de 65 anos, portador de policitemia vera, que evoluiu com aparecimento de síndrome de Sweet na sua forma paraneoplásica.

Palavras-chave: Fator estimulador de colônias de granulócitos; Macrófagos; Policitemia vera; Síndrome de Sweet
\end{abstract}

\begin{abstract}
Sweet's syndrome may be associated with hematological malignancies, particularly with acute myelogenous leukemia, but there are few reports of its association with polycythemiavera. We describethe case of a 65 -year-old male patient, diagnosed with polycythemiavera, which developedinto paraneoplastic Sweet's syndrome.

Keywords: Granulocyte-macrophage colony-stimulating factor; Macrophages; Polycythemia vera; Sweet's syndrome
\end{abstract}

\section{INTRODUÇÃO}

A policitemia vera (PV) é desordem clonal de células progenitoras multipotentes da medula óssea, caracterizada por hiperplasia das linhagens de células hematopoiéticas e por aumento da massa eritrocitária, leucocitose e trombocitose. As manifestações clínicas são variadas; sua terapêutica é direcionada para a redução de volume e viscosidade sanguíneos e do número de plaquetas, por meio de flebotomia, administração de fósforo radioativo e outros agentes quimioterápicos. Alguns casos podem evoluir para leucemia mieloide aguda e mielofibrose. ${ }^{1}$

Descrita, originalmente, por Robert Douglas Sweet, em 1964, ${ }^{2}$ a síndrome de Sweet (SS) é doença rara, de etiologia desconhecida, com surgimento súbito de placas ou nódulos eritematodolorosos, especialmente, na face, pescoço e extremidades superiores, associados a febre e leucocitose neutrofílica. Predomina em mulheres, entre 30 e 50 anos, sem pre- dileção racial. Pode ser classificada em cinco grupos: idiopático ou clássico, parainflamatório, paraneoplásico, associado à gestação e secundário a drogas. Corticoides sistêmicos são a terapêutica de escolha e determinam rápida resposta clínica. ${ }^{3.5}$

A SS pode estar associada a malignidades em $20 \%$ dos casos, ${ }^{3,6}$ em especial, a leucemia mieloide aguda. Existem poucos relatos de associação com a policitemia vera. Relata-se o caso de doente do sexo masculino, de 65 anos, portador de PV, que evoluiu com aparecimento de lesões cutâneas compatíveis com SS na sua forma paraneoplásica.

\section{RELATO DO CASO}

Homem de 65 anos, branco, deu entrada no serviço de dermatologia relatando, há um ano, episódios recorrentes de lesões papulosas, pequenas e avermelhadas nas mãos, que evoluíam com bolhas

\footnotetext{
Recebido em 19.05.2008.

Aprovado pelo Conselho Consultivo e aceito para publicação em 31.07.09

* Trabalho realizado no Serviço de Dermatologia da Universidade Federal Fluminense (UFF) - Niterói (RJ), Brasil.

Conflito de interesse: Nenhum / Conflict of interest: None

Suporte financeiro: Nenhum / Financial funding: None

Pós-graduanda do Serviço de Dermatologia da Universidade Federal Fluminense (UFF) - Niterói (RJ), Brasil.

Pós-graduanda do Serviço de Dermatologia da Universidade Federal Fluminense (UFF) - Niterói (RJ), Brasil.

Professora titular e chefe do Serviço de Dermatologia da Universidade Federal Fluminense (UFF) - Niterói (RJ), Brasil.

Professora adjunta do Serviço de Dermatologia da Universidade Federal Fluminense (UFF) - Niterói (RJ), Brasil.

Professora adjunta do Serviço de Dermatopatologia da Universidade Federal Fluminense (UFF) - Niterói (RJ), Brasil.

(C)2009 by Anais Brasileiros de Dermatologia
} 
dolorosas, sempre acompanhadas de febre de $38^{\circ} \mathrm{C}$. A revisão dos sistemas foi normal, sem evidências de linfoadenomegalias ou organomegalias. Ao exame, havia lesões bolhosas de conteúdo seropurulento, variando de $0,5 \mathrm{~cm}$ a $2,0 \mathrm{~cm}$, circundadas por eritema, localizadas nas palmas e na falange distal do quarto quirodáctilo esquerdo (Figuras 1 e 2); lesões purpúricas encimadas por pequenas pústulas, medindo cerca de $0 \mathrm{~cm}$ e localizadas no dorso dos pés (Figura 3). As mucosas estavam poupadas.

Foram levantadas as hipóteses diagnósticas de SS e vasculite. Os exames laboratoriais demonstraram hematócrito de 40,5\%, 4.400 leucócitos (com contagem de neutrófilos normal), 14.2000 plaquetas e velocidade de hemossedimentação de $50 \mathrm{~mm} / \mathrm{h}$. Realizaram-se os seguintes exames: função hepática, eletrólitos, creatinina, ureia, urina, radiografia simples de tórax e ultrassom abdominal, com resultados dentro do limite da normalidade. A biópsia da pele mostrou edema da derme papilar, denso infiltrado de neutrófilos na derme, dissociando fibras colágenas; leucocito-

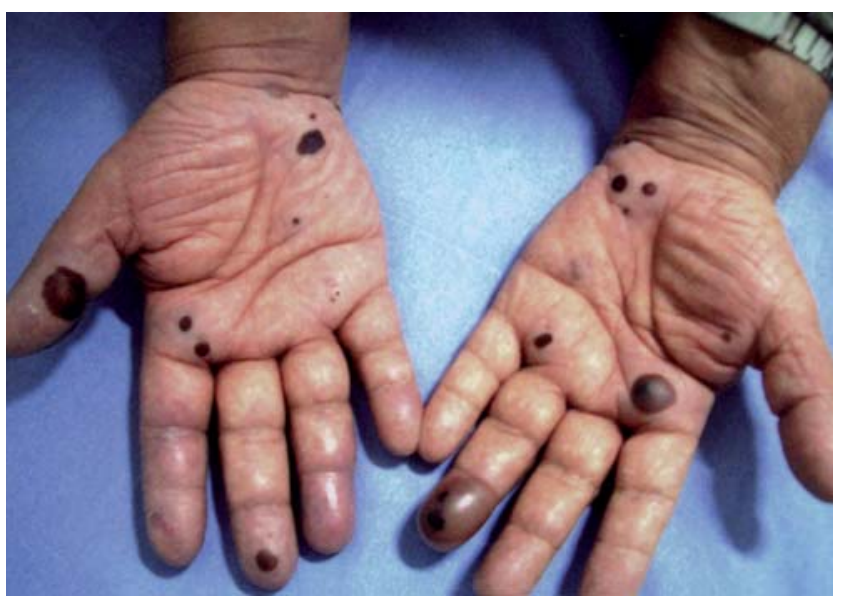

Figura 1: Lesões bolhosas nas palmas e na falange distal do $4^{\circ}$ quirodáctilo esquerdo e pápulas enegrecidas nas palmas e nas falanges distais do $1^{\circ}$ e $3^{\circ}$ quirodáctilos direitos

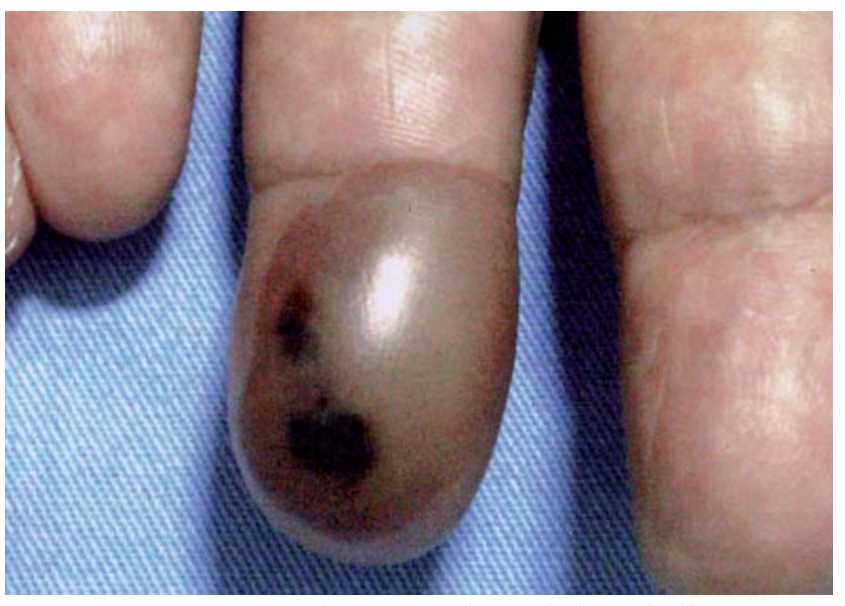

Figura 2: Conteúdo seropurulento da lesão bolhosa clasia e extravasamento de hemácias estavam presentes, confirmando o diagnóstico da SS (Figura 4). Com o início da administração de prednisona $(0,5 \mathrm{mg} / \mathrm{kg} / \mathrm{dia})$, houve resposta imediata e clareamento completo das lesões em um mês. Não se observaram recidivas durante um ano de acompanhamento.

O diagnóstico da PV havia sido feito há dois anos, durante a investigação de emagrecimento e pletora facial, com hematócrito de 51,2\%, hemoglobina de $17,8 \mathrm{~g} / \mathrm{dl}$, 16.200 leucócitos e 476.000 plaquetas. Desde então, ministrou-se hidroxiureia oral (500mg/dia) e fizeram-se duas flebotomias com o objetivo de manter o hematócrito menor que $45 \%$, com controle do quadro.

\section{DISCUSSÃO}

A SS está relacionada a neoplasias em $20 \%$ dos casos ${ }^{3,6}$ sendo que $85 \%$ destes estão relacionados a transtornos hematológicos e $15 \%$, a tumores sólidos. Em relação às neoplasias hematológicas, é mais frequentemente observada a leucemia mieloide aguda; quanto aos tumores sólidos, $2 / 3$ correspondem a carcinomas do trato geniturinário. ${ }^{3}$

A forma paraneoplásica da SS acomete igualmente homens e mulheres com idades entre 60 e 70 anos, diferentemente da forma clássica. As manifestações clínicas podem ser mais graves e atípicas do que nesta, com presença de pústulas, bolhas, úlceras e púrpuras. Além da localização habitual, distribuem-se, também, nos membros inferiores, tronco e dorso. Manifestações extracutâneas e acometimento da mucosa oral podem se desenvolver. As recorrências clínicas são frequentes e concomitantes com as recidivas tumorais. $\mathrm{O}$ achado laboratorial de anemia, a contagem anormal de plaquetas e a ausência de leucocitose neutrofílica refletem a história natural da neoplasia hematológica de base ou do tratamento quimioterápico. A presença e recorrência das bolhas hemorrágicas e das lesões purpúricas, bem como as alterações laboratoriais, chamaram a atenção das autoras para associação com doença de base. . $^{3,6,7}$

Apenas sete casos de associação entre a PV e a SS foram relatados na literatura. ${ }^{6-12}$ Em cinco deles, a PV antecedeu o início da SS em 2 a 18 anos e, em dois, as lesões cutâneas ocorreram de forma intermitente, 4 a 13 anos antes do início da desordem hematológica.6-8 A progressão para mielofibrose foi relatada em dois $\operatorname{casos}^{8,9} \mathrm{e}$, para leucemia mieloide aguda, em apenas um. ${ }^{10}$ Nos demais pacientes, não se observou progressão ou transformação para estágios mais agressivos. No caso descrito, a PV precedeu a SS em dois anos, sem concomitância com a progressão da desordem hematológica. O paciente está sendo acompanhado rigorosamente, uma vez que a recorrência das lesões cutâneas é sinal de mau prognóstico, pela pos- 


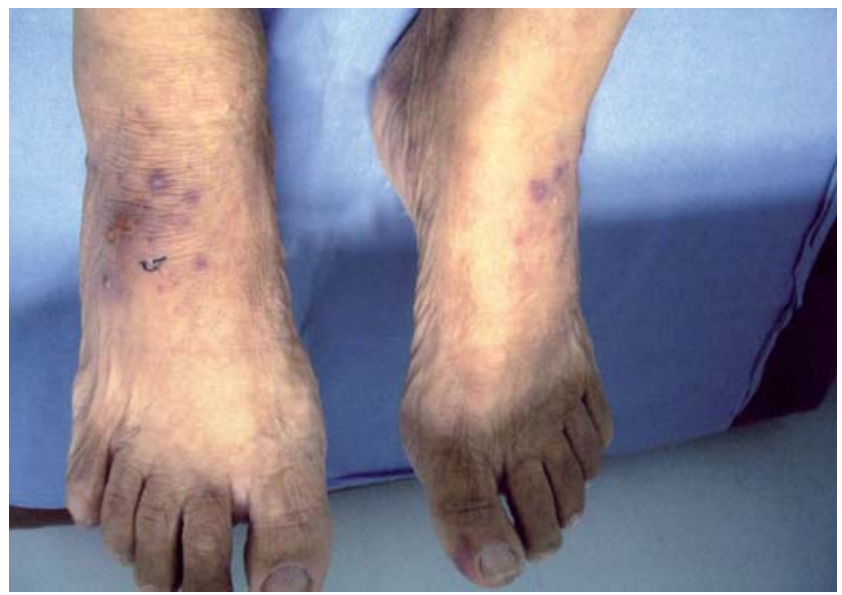

FIGURA 3: Lesões purpúricas encimadas por pequenas pústulas localizadas no dorso dos pés

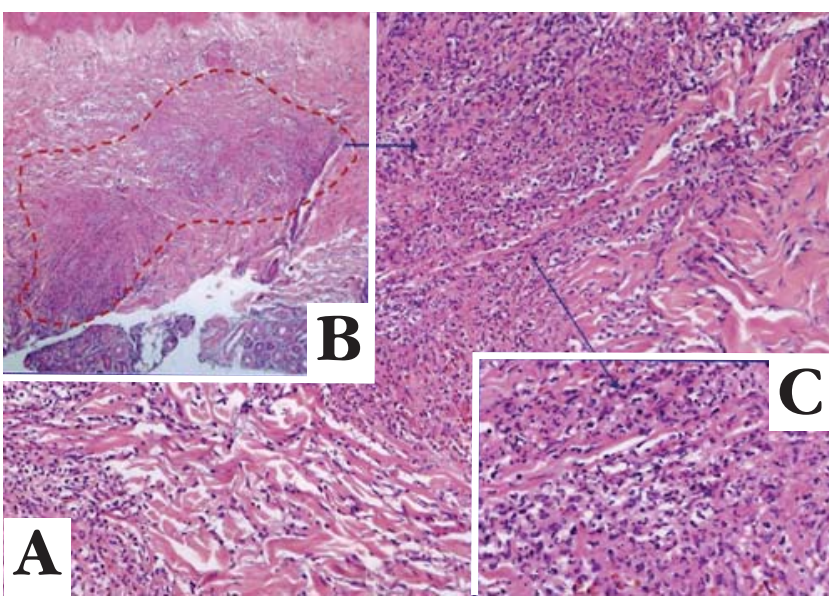

Figura 4: A. Síndrome de Sweet (H\&E, 40x); B. A derme contém denso infiltrado inflamatório intersticial (H\&E, 100x); C: Infiltrado constituído por neutrófilos com leucocitoclasia e extravasamento de hemácias (H\&E, 400x)

Mediante os dados expostos, acredita-se que, provavelmente, a associação da SS com a PV represente uma anormalidade nos fatores responsáveis pelo controle da proliferação celular em indivíduos susceptíveis e o principal mecanismo para explicar a associação entre essas duas patologias seria o GM-CSF liberado por células tumorais ou histiócitos infiltrantes ou, ainda, por células epidérmicas estimuladas.

Aspecto interessante é a ocorrência da SS relatada por Awan et al. ${ }^{5}$ em paciente com intensa neutropenia, embora agregados neutrofílicos sejam encontrados na derme desses pacientes. Tais aspectos sugerem que a presença desses infiltrados não seja, obrigatoriamente, de origem medular e que eles possam ocorrer sob duas condições: a primeira, que células multipotentes, residentes no território cutâneo, possam se desenvolver em linhagem neutrofílica; a segunda, mais aceitável, é que, durante a ativação de células cutâneas em uma reação inflamatória, haja produção de GM-CSF, com requisição de células multipotentes medulares que se diferenciam no território cutâneo. Se confirmada essa hipótese, sugere-se que pacientes portadores de SS devam ser tratados, por longo tempo, com corticoides sistêmicos, visando à supressão da requisição de células medulares multipotentes e possibilitando maior estabilidade medular.

Relata-se mais um caso de SS associada à PV, enfatizando-se a importância da investigação rotineira de malignidades, em especial, hematológicas. Nos pacientes com desordens mieloproliferativas, a SS pode significar prognóstico desfavorável, necessitando de um acompanhamento rigoroso, em vista da possibilidade de conversão para leucemia mieloide aguda. 


\section{REFERÊNCIAS}

1. Geissler K, Öhler L, Födinger M, Kabrna E, Kollars M, Skoupy $\mathrm{S}$ et al. Interleukin-10 inhibits erythropoietinindependent growth of erythroid burst in patients with polycythemia vera. Blood. 1998;92:1967-72.

2. Sweet RD. An acute febrile neutrophilic dermatosis. Br J Dermatol. 1964;76:349-56.

3. Franco M, Giusti C, Malieni D, Ferrario D, Galimberti G, Parra IH et al. Síndrome de Sweet associada a neoplasias. An Bras Dermatol. 2006;81:473-82.

4. Giasuddin AS, El-Orfi AH, Ziu MM, El-Barnawi NY. Sweet's syndrome: is the pathogenesis mediated by helper T cell type 1 cytokines? J Am Acad Dermatol. 1998;39:940-3.

5. Awan F, Hamadani M, Devine S. Paraneoplastic Sweet's syndrome and the pathergy phenomenon. Ann Hematol. 2007;86:613-4.

6. Vázquez MG, Sánches-Aguilar D, Peteiro C, Toribio J. Sweet's syndrome and polycythaemia vera. J Eur Acad Dermatol Venereol. 2005;19:382-3.

7. Wong GAE, Guerin DM, Parslew R. Sweet's syndrome and polycythaemia rubra vera. Clin Exp Dermatol. 2000;25:296-8.

8. Grob JJ, Mege JL, Prax AM, Bonerandi JJ. Disseminated pustular dermatosis in polycythaemia vera. J Am Acad Dermatol. 1988;18:1212-8.

9. Singh M, Kaur S. Sweet's syndrome and polycythaemia vera. Br Med J. 1985;291:1542.

10. Horan MP, Remond J, Gehle D, Dabe IB, Fort SL. Postpolycythemic myeloid metaplasia, Sweet's syndrome and acute myeloid leukemia. J Am Acad Dermatol. 1987;16:458-62.
11. Furukawa T, Takahashi $M$, Shimada $H$, Moriyama $Y$, Shibata A, Katsumi S. Polycythaemia vera with Sweet's syndrome. Clin Lab Haematol. 1989;11:67-70.

12. Cox NH, Leggat H. Sweet's syndrome associated with polycythaemia rubra vera. J Am Acad Dermatol. 1990;23:1171-2.

13. White JM, Mufti GJ, Salisbury JR, du Vivier AW. Cutaneous manifestations of granulocyte colony-stimulating factor. Clin Exp Dermatol. 2006;31:206-7.

14. Oehler L, Kollars M, Bohle B, Berer A, Reiter E, Lechner $\mathrm{K}$ et al. Interleukin-10 inhibits burst-forming uniterythroid growth by suppression of endogenous granulocyte-macrophage colony-stimulating factor production from T cells. Exp Hematol. 1999;27:217-23.

15. Stoebner PE, Rahmoun M, Ferrand C, Meunier L, Yssel $\mathrm{H}$, Pène $\mathrm{J}$. A single sub-erythematous exposure of solar-stimulated radiation on the elicitation phase of contact hypersensitivity induces IL-10-producing $T$ regulatory cell in human skin. Exp Dermatol. 2006;15:615-24.

\footnotetext{
ENDEREÇO PARA CORRESPONDÊNCIA / MAILING ADDRESS: Ângela Puccini Moreira

Rua Senador Vergueiro, 238 - Ap. 914

Flamengo

22230001 Rio de Janeiro - RJ - Brasil

Tel.:/Fax: 2181110355

e-mail: angelapuccini@bol.com.br
}

Como citar este artigo / How to cite this article: Moreira AP, Souza FF, Gaspar NK, Quattrino AL, Vilar EAG. Síndrome de Sweet associada à policitemia vera. An Bras Dermatol. 2009;84(6):663-6. 